\title{
Development of the quality of additional professional programs through the introduction of the principle of transformability
}

\author{
Anatoly Annin ${ }^{1}$, Andrey Ashin ${ }^{1}$, Maria Gachava ${ }^{2}$, Olga Kotlyarova ${ }^{3}$, and Elena Potapova ${ }^{1}$ \\ ${ }^{1}$ Russian Academy of National Economy and Public Administration Under the President of the \\ Russian Federation, Department of State and Municipal Administration of the Vladimir Branch of \\ RANEPA, Vladimir, Russia \\ ${ }^{2}$ Vladimir State University named after A.G. and N.G. Stoletov, M.M. Speransky Law Institute, \\ Department of Criminal Law Disciplines, Vladimir, Russia \\ ${ }^{3}$ Russian Academy of National Economy and Public Administration Under the President of the \\ Russian Federation, Department of Social and Humanitarian Disciplines, Vladimir Branch of \\ RANEPA, Vladimir, Russia
}

\begin{abstract}
Development and implementation of the transformability principle have been preceded by insufficient satisfaction of trainees, federal and municipal officers in particular, with the quality of conventional supplemental professional programs of further training, as well as their low motivation to learning and improvement of professional competences. This article is aimed at analysis of efficiency of implementation of transformability principle into supplemental professional programs of further training. Focused interview and focus groups method by R. Merton were the main research method. This procedure was applied during training of two focus groups according to transformable supplemental professional program titled Manage by word, aimed at development of communication competences of government representatives (309 civil officers of Tambov oblast) and officers and heads of multifunctional centers of state and municipal services (58 persons). The term "transformability" implies structuring of education route by trainees themselves as well as existence of mandatory and variable elements allowing to adapt the program content to various targeted audiences. The main results of the work have been confirmation of satisfaction of trainees with the quality of transformable supplemental professional program and improved motivation to learning.
\end{abstract}

Keywords: supplemental professional training, further education programs, motivation, transformability principle.

\section{Introduction}

Distance activity during the lockdown stipulated by COVID-19 epidemic increases importance of digital distance learning technologies.

*Corresponding author: annin a@vlad.ranepa.ru 
Foreign researchers pay peculiar attention to opportunities of digital transformations in education. Digital transformation is systematic improvement of education by means of intelligent technologies and digital tools.

Thus, for instance, on the basis of empirical studies performed among academicians, Turkish colleagues mention obligation of strategic vision of digital transformations, assuming variation of education system from bottom to top: from student and parents to teacher and head. Such digital education transformations are based on the principle of consciousness [1].

The researchers of University of Public Administration in Ludwigsburg and University of Zurich see the prospects of digital education in combination of practice of independent solution to the problems of real world with scientific constituent [2].

Digital transformations of education in Germany are aimed at improvement of student's perception and teacher's activities by digital media [3].

The system of Russian supplemental professional training is also exposed to transformations. However, there are some global challenges creating barrier for a trainee to obtain modern digital skills. First of all, this is the lack of motivation to training. According to the opinion of professors of Higher School of Economics, motivation and independence should be considered as factors related with the efficiency of digital solutions and digitalization in whole [4].

In this regard, the quality of education content and promotion of motivation activity could be improved by transformable supplemental professional programs.

The term "transformability" implies 1) existence of mandatory and variable elements in program content; 2) structuring of education route by trainees themselves: free selection of topics and modules, arrangement of individual education route, adjustment of program scope and time for its studying.

The transformability principle is applied regularly at various stages of education. For instance, positive influence on formation of flexible skills of spatial imagination of child not only by transformer toys but also by transformer package is studied $[5,6,7]$.

The transformability technologies are implemented into the paradigm of secondary education. The concepts of transformability aids for various subjects attract interest. Nonconventional visualization of educational material promotes its acquisition and memorization $[8,9,10]$.

Transformability technologies can also be used for optimization of education space. Innovative design solutions allow to transform education entity, which serves for more economic use of space and equipment $[11,12]$.

The concept of multifunctionality of transformability approach is demanded at the stage of higher education. For instance, in the work of N. V. Kuzina, the transformability technology is combination of postgraduate training with implementation of programs of supplemental professional training [13].

There are few works on analysis of transformability principle in the area of supplemental professional training. This is unreasonable, since the supplemental professional programs of further training can be transformed in order to improve their efficiency.

\section{Methods}

The transformability principle was verified by implementation of the transformable supplemental professional program of further training titled Manage by word. While identifying the study procedure of efficiency of the transformability principle in supplemental training, we selected the focused interview and focus groups method by R. Merton [14]. The first focus group was comprised of 309 civil officers of Tambov oblast. 
The study was performed from March, 2019 to March, 2020. The second focus group was comprised of 58 officers and heads of multifunctional centers of Rostov oblast. The study was performed from October, 2019 to March, 2020. According to the opinion by N.V. Veselkova, in focus groups the interactions are important which take place between participants during group formation and further group dynamics, this property of focus groups originates from group discussion [15, p. 419].

The supplemental professional program of further training (Manage by word) is comprised of three modules. The first module, Efficient communication with citizens, is aimed at elimination of communication barriers between government officers and population. The second module, Communication in project teams, is oriented at improvement of professional interaction between colleagues, within the team. The third module, Word as management tool, is intended for heads, this module is devoted to subordinative communication between the head and his subordinates. Despite the fact that subdivision into modules assumed distinct delineation of educational request: improvement of communication with citizens, with colleagues, or with heads, transformability of the program allowed independent structuring of education route by trainees.

\section{Results}

The program was performed in distance format. Motivation of trainees and satisfaction with quality of education content were analyzed in three face-to-face steps. The first step: before the training. The second step: in the middle of the training. The third step: before the last exams and final testing. Each face-to-face step assumed measurement of trainee motivation to obtain supplemental professional education.

The members of focus groups were asked six questions, which became evaluation criteria of motivation to train. It was required:

1) to select one or several modules of program study: the higher was the number of modules required by the trainee, the higher was his motivation to study;

2) to select any number of topics from any modules: increase in the number of selected topics assumed higher concern of the trainee, his readiness to improve the existing knowledge;

3) to identify a module or an area potentially promising for the next training step: the desire to independently formulate the training area evidenced increased motivation to training;

4) to propose a topic, which was unavailable in the program modules but important for a certain trainee: independent structuring of education route evidenced formation of individual education request;

5) to request for more detailed presentation of supplemental material: such request evidenced readiness to independent work and high motivation to study;

6) to change the scope of educational program: increase in class hours for studying the program modules in combination with higher number of selected topics confirmed increase in motivation to study.

The dynamics of motivation activity of trainees are illustrated in Fig. 1. Each criterion corresponds to the number in the list. 


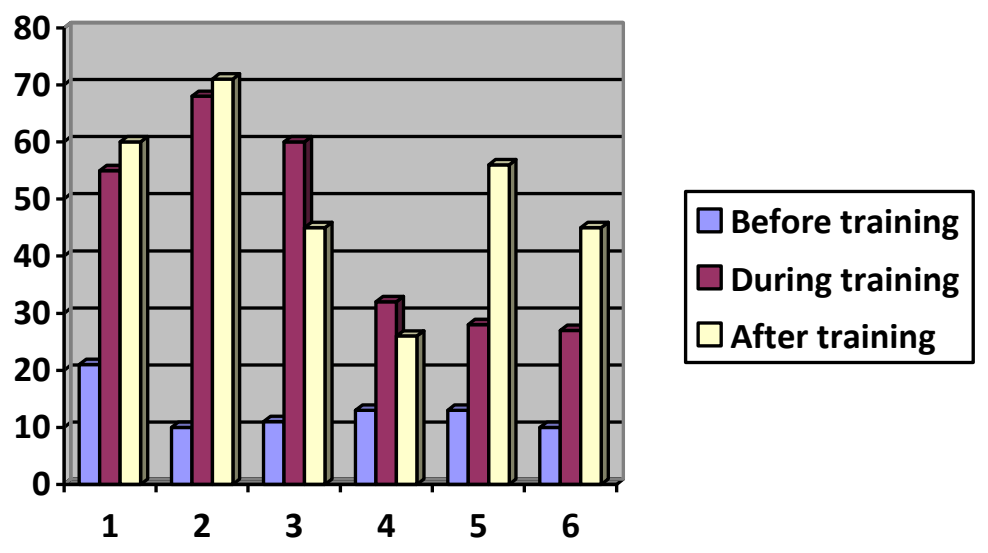

Fig. 1. The dynamics of motivation activity of trainees.

The vertical axis demonstrates the percent of trainees estimating each of the six criteria. The blue column illustrates response of the trainees before training, the dark red column during training, and the beige column - before the last exams. The figure demonstrates the increase of trainee activity in studying supplemental professional program and increase in motivation.

\section{Discussion}

The respondents structured individual education route comprised of 3 modules, 7 topics in each module.

1) Survey of the focus groups before training demonstrated that only $13 \%$ of trainees selected 2 modules of the program, 63\% - only 1 module. The second survey (during training) demonstrated that $26 \%$ of trainees wanted to select supplemental module. Before the last exams $56 \%$ of respondents requested for the second module and $17 \%$ decided to study the third module.

2) The second criterion, Selection of any number of topics from any modules, demonstrated the following results. Before training $45 \%$ of respondents selected minimum number of topics for study: 3 topics. Only $10 \%$ of the surveyed selected more than 6 topics. During the training the number of active trainees increased to $67 \%$. Before the last exams $70 \%$ of respondents selected more than 6 topics. The range of the selected topics increased more than by $50 \%$. This obviously evidenced increased motivation of the trainees. It should be mentioned that the most demanded topics were as follows: 1) conflict situation, overriding of verbal and nonverbal aggression; 2) efficient communication in human-tohuman professions; 3 ) techniques of efficient communication (requested by more than $50 \%$ of the trainees); 4) significance of literate speech for efficient manager; 5) manipulation as a method of impact on interlocutor; 6) public speech as a powerful tool of influence (requested more than by $45 \%$ of the trainees).

3) Only $11 \%$ of the surveyed persons agreed to identify module or area potentially promising for training before training, $60 \%$ of the trainees did it during the training, and $45 \%$ of the trainees - before the last exams. We believe that the decrease in this indicator before the last exams should be attributed to satisfaction of the trainees with the education demand at the second step. 
4) Independent formulation of educational demand was the most difficult before training, the trainees were asked to suggest topic, which was unavailable in the program modules but which was individually important. Before training only $13 \%$ of trainees formulated a topic of their concern, $31 \%$ did it during training, and $25 \%$ - before the last exams. Comprehension and formulation of own educational demand was an evidence of high motivation to training. In terms of percent, this criterion was characterized by the weakest indicator. However, positive dynamics could be observed.

5) Initially only $13 \%$ participants in the focus groups requested for more detailed presentation of supplemental material (methodological support). During the training the percent of the participants in the focus groups ready for independent work increased to $26 \%$ and finally to $56 \%$. We believe that the desire to perform more independent assignments and to study supplemental material evidenced the trainees' concern in acquisition of new skills and increase in motivation.

6) The change of scope of education program, i.e. increase in class hours for its studying, as well as opportunity to study supplemental modules before training did not meet positive response of the audience. The trainees did not identify reasons to increase the scope of twenty-four-hour supplemental professional program. However, during the third step about one half of the respondents (45\%) formulated supplemental educational request, attributing this to interest to education format, importance of topics, ease of material studying.

\section{Conclusion}

The obtained results confirm that freedom in selection of modules and topics of program, formulation of individual educational request, opportunity to increase the program scope and to request for more supplemental material stimulate activity of trainees and increase their motivation. All criteria of efficiency of transformability principle demonstrate positive dynamics. The portion of trainee involvement into program studying increased, the portion of independently formulated educational requests and urgent topics increased. Such positive variations are observed for participants of both focus groups.

We believe that the transformability principle applied to supplemental professional programs of further training promotes independence of trainees and improves their motivation not only to training but also to professional activity.

\section{References}

1. A. Balyer, Ö. Öz, International Online Journal of Education and Teaching (IOJET), 5(4), 809-830 (2018)

2. B. Schenk, M. Dolata, Facilitating digital transformation through education: a case study in the public administration, in Proceedings of the 53rd Hawaii International Conference on System Sciences, University of Hawaii at Manoa, 7-10 January 2020, Maui, Hawaii, US (2020)

3. M. Bond, V.I. Marín, C. Dolch, S. Bedenlier, O. Zawacki-Richter, International Journal of Educational Technology of Higher Education, 78, 2-20 (2018)

4. E. Gable, Digital transformation of school education. International Experience, Trends, Global Recommendations (Higher School of Economics Publishing House, Moscow, 2019) 
5. Transformer toy. Russian patent of 2012 on IPC A63F9/08. Description of the patent for invention RU2459649C1. Accessed on: December 10, 2020. [Online]. Available: https://patenton.ru/patent/RU2459649C1

6. K.M. Vander Heyden, M. Huizinga, J. Jolles, Developmental Psychology, 53(2), 290305 (2017)

7. S.C. Levine, K.R. Ratliff, J. Huttenlocher, J. Cannon, Developmental Psychology, 48(2), 530-542 (2012)

8. F.F. Arduvanova, V.E. Steinberg, Education and Science, 3(33), 85-89 (2005)

9. M.Yu. Zabruskova, N.F. Ryabov, S.Yu. Sher, T.V. Mukhametzyanov, A.A. Mustafina, T.V. Smirnova, D.R. Galiakberova, Izvestia of Kazan State University of Architecture and Civil Engineering, 1(3), 119-125 (2005).

10. L.A. Zavershinskaya, Kaliningrad Education Bulletin, 2(6), 92-104 (2020)

11. H. Daniels, H.M. Tse, Design As a Social Practice, in Making Education: Material School Design and Educational Governance. Educational Governance Research, 9 (Springer, Cham, 2009)

12. R. Leiringer, P. Cardelilino, British Educational Research Journal, 37(6), 915-934 (2011). https://doi.org/10.1080/01411926.2010.508512

13. N.V. Kuzina, Problemy i perspektivy razvitiya obrazovaniya v Rossii, 39, 133-137 (2016)

14. R. Merton, M. Fiske, P. Kendall, The Focused Interview: A Manual of Problems and Procedures (The Free Press, Glencoe, Illinois, 1991)

15. N.V. Veselkova, Praktiki govoryat, 4, 418-426 (2019) 